\title{
Sagittal alignment changes and postoperative complications following surgery for adult spinal deformity in patients with Parkinson's disease: a multi- institutional retrospective cohort study
}

\author{
Atsuyuki Kawabata ${ }^{1}$, Toshitaka Yoshii ${ }^{*}$, Kenichiro Sakai $^{2}$, Takashi Hirai ${ }^{1}$, Masato Yuasa ${ }^{1}$, Hiroyuki Inose ${ }^{1}$,
} Yu Matsukura', Shingo Morishita', Masaki Tomori ${ }^{2}$, Ichiro Torigoe ${ }^{2}$, Kazuo Kusano ${ }^{3}$, Kazuyuki Otani ${ }^{3}$, Yoshiyasu Arai², Shigeo Shindo ${ }^{3}$ and Atsushi Okawa'

\begin{abstract}
Background: Parkinson's disease (PD) has been found to increase the risk of postoperative complications in patients with adult spinal deformity (ASD). However, few studies have investigated this by directly comparing patients with PD and those without PD.

Methods: In this multicenter retrospective cohort study, we reviewed all surgically treated ASD patients with at least 2 years of follow-up. Among them, 27 had PD (PD+ group). Clinical data were collected on early and late postoperative complications as well as any revision surgery. Radiographic parameters were evaluated before and immediately after surgery and at final follow-up, including sagittal vertical axis (SVA), thoracic kyphosis, lumbar lordosis, sacral slope, and pelvic tilt. We compared the surgical outcomes and radiographic parameters of PD patients with those of non-PD patients.
\end{abstract}

Results: For early complications, the PD+ group demonstrated a higher rate of delirium than the PD- group. In terms of late complications, the rate of non-union was significantly higher in the PD+ group. Rates of rod failure and revision surgery due to mechanical complications also tended to be higher, but not significantly, in the PD+ group ( $p=0.17, p=0.13$, respectively). SVA at final follow-up and loss of correction in SVA were significantly higher in the PD+ group.

Conclusion: Extra attention should be paid to perioperative complications, especially delirium, in PD patients undergoing surgery for ASD. Furthermore, loss of correction and rate of non-union were greater in these patients.

Keywords: Adult spinal deformity, Parkinson's disease, Postoperative complications, Sagittal alignment, Sagittal vertical axis, Radiographic parameters

\footnotetext{
* Correspondence: yoshii.orth@tmd.ac.jp

${ }^{1}$ Department of Orthopedic Surgery, Tokyo Medical and Dental University, Chome-5-45 Yushima, Bunkyo City, Tokyo 113-8510, Japan

Full list of author information is available at the end of the article
}

C C The Author(s). 2021 Open Access This article is licensed under a Creative Commons Attribution 4.0 International License, which permits use, sharing, adaptation, distribution and reproduction in any medium or format, as long as you give appropriate credit to the original author(s) and the source, provide a link to the Creative Commons licence, and indicate if changes were made. The images or other third party material in this article are included in the article's Creative Commons licence, unless indicated otherwise in a credit line to the material. If material is not included in the article's Creative Commons licence and your intended use is not permitted by statutory regulation or exceeds the permitted use, you will need to obtain permission directly from the copyright holder. To view a copy of this licence, visit http://creativecommons.org/licenses/by/4.0/. The Creative Commons Public Domain Dedication waiver (http://creativecommons.org/publicdomain/zero/1.0/) applies to the data made available in this article, unless otherwise stated in a credit line to the data. 


\section{Background}

Parkinson's disease (PD) is a neurodegenerative disorder, and the main symptoms include rigidity, bradykinesia, and gait disorder. As a result of population aging, the number of patients with this age-related disorder is on the rise [1]. In severe cases, PD can lead to postural disorders, such as anterocollis, Pisa syndrome, and camptocormia [2-5]. Studies have reported that these various postural abnormalities can increase susceptibility to development of rigid spinal deformities $[2,3]$ and that patients with PD develop adult spinal deformity (ASD) more frequently than the general population in the same age group [6].

Recent studies have found that ASD negatively affects health-related quality of life [7, 8]. Surgical treatment has been shown to provide better health-related quality of life outcomes than non-surgical treatment, especially in patients with severe deformity [9]. However, higher complication rates have been reported, with reoperation rates reaching up to $47 \%[10,11]$. Surgical complications are generally classified as perioperative or late complications. Perioperative complications include epidural hematoma, deep vein thrombosis (DVT), and pulmonary embolism (PE), which usually appear during or soon after surgery. Late complications include junctional kyphosis, rod fractures, and non-union, which usually develop more than 1 month after surgery and are mainly caused by continuous mechanical stress.

Generally, PD patients are presumed to be at higher risk of surgical complications, especially mechanical complications due to postural instability, a higher risk of falls, and decreased bone quality [12-15]. However, to date, only a few small case series have investigated complications after surgery for ASD in PD patients [16-19]. In addition, risk factors for complications and revision surgery in PD patients have not yet been confirmed. Therefore, we conducted this multicenter study in order to investigate 234 surgically treated ASD patients with at least 2 years' follow-up. We compared surgical outcomes and radiographic parameters of PD patients with those of non-PD patients.

\section{Methods}

This retrospective observational cohort study follows the Strengthening the Reporting of Observational studies in Epidemiology (STROBE) guidelines. We reviewed 234 ASD patients treated surgically from January 2009 to December 2016 at our hospital and affiliated institutions. Institutional review board approval was obtained at each site for the patient enrolment and data collection protocols. Inclusion criteria were age $\geq 21$ years at surgery, follow-up period of $\geq 2$ years, and surgery including posterior instrumentation of four spinal levels with sufficient radiographic data. In total, 27 patients with PD were identified. Data were collected on mean PD duration, Hoehn and Yahr (HY) stage, and medication for PD.

A diagnosis of ASD was made if at least one of the following was present: a coronal Cobb angle $>20^{\circ}$, a sagittal vertical axis $>5 \mathrm{~cm}$, pelvic tilt $>25^{\circ}$, and thoracic kyphosis $>60^{\circ}$. Etiologies included degenerative kyphosis/ kyphoscoliosis, post-lumbar surgery, and previous vertebral fracture. Operating time and intraoperative blood loss were recorded. Surgical complications are generally classified as early or late. Early complications were defined as those that occurred during or within 1 month following surgery and included neurological disorders, implant failure, DVT, PE, cerebrovascular disease, respiratory disorders, cardiovascular disorders, delirium, surgical site infection, and spinal epidural hematoma. The number of revision surgeries due to perioperative complications was also recorded. Late complications usually occur more than 1 month after surgery and are primarily due to continuous mechanical stress. This stress leads to failure of either the hardware or the vertebra and is defined as a mechanical complication, including, for example, proximal junctional kyphosis (PJK), distal junctional kyphosis, non-union, rod breakage, and vertebral fracture. PJK was defined by two spine surgeons using the following criteria: 1) kyphosis $>10^{\circ}$ between the upper-instrumented vertebra and two-level proximal vertebra and 2) a change of $\geq 10^{\circ}$ from the preoperative measurement [20]. Non-union was defined as 1) loss of fixation (e.g., implant breakage/dislodgement of rods or hooks) or a halo $(2-4 \mathrm{~mm})$ around a pedicle screw, 2) progression of deformity with or without pain in the fused segments, 3) collapse of the disc space during follow-up or gas in the disc space, and 4) motion $\left(\geq 3^{\circ}\right)$ on plain flexion/extension radiographs [21]. Mechanical failure was defined as mechanical complications requiring revision surgery.

We collected demographic and clinical data including age, sex, BMI, medical comorbidities, and femoral neck bone mineral density (BMD). Measurements on radiographs included SVA, thoracic kyphosis (T4-T10), thoracolumbar kyphosis (T10-L2), lumbar lordosis (LL; L1-S1), sacral slope, pelvic incidence (PI), and pelvic tilt. These parameters were evaluated in the standing position both before and at 4 weeks post-surgery. X-ray images were also evaluated at the final follow-up. A threecolumn osteotomy was defined as a procedure using pedicle subtraction osteotomy or vertebral column resection. A radiographic parameter of $-10^{\circ}<\mathrm{PI}-\mathrm{LL}<10^{\circ}$ was defined as ideal alignment based on the SRS-Schwab ASD classification.

We compared the surgical outcomes and radiographic parameters of PD patients (the PD+ group) with those of the non-PD patients (the PD- group). Statistical analysis 
was performed using IBM SPSS Statistics for Macintosh, Version 25.0 (IBM Corp, Armonk, NY). We used a paired t-test or chi-squared test to compare the PD+ and the PD- groups. Also, t-tests were used to compare the means of continuous variables, and chi-square tests were used to compare the proportions of categorical variables between the groups. A $p$-value $<0.05$ was considered statistically significant. Missing values were imputed using the last observation carried forward method. We also matched the background data using propensity score matching, a technique that has been extensively used to adjust for known confounding biases [22-24]. The propensity score for mechanical failure was initially calculated using the following variables: patient age and sex, BMI, fusion levels, and preoperative SVA. We performed the procedure using a logistic regression model. The $\mathrm{C}$-statistic suggested that the fit was 0.67 , which is a fairly good score. Patients in the two study groups were matched based on propensity scores, with the condition that the caliper be lower than 0.2. Twenty-four pairs of patients with and without PD were created after matching. Postoperative complications in the matched cases were compared between the two groups.

\section{Results}

Table 1 shows the patient characteristics of the PD+ group and the PD- group. There was no significant difference between the two groups with respect to age, sex, BMI, or BMD. The number of fixed spinal levels was significantly higher in the PD+ group than in the PDgroup $(9.3 \pm 2.6$ vs $7.8 \pm 1.9, p=0.006)$, and the rates of three-column osteotomy tended to be higher in the PD+ group $(63.0 \%$ vs $48.5 \%, p=0.14)$. For preoperative radiographic parameters, SVA was significantly higher in the $\mathrm{PD}+$ group than in the PD- group $(196.0 \pm 63.8 \mathrm{~mm}$ vs $135.4 \pm 69.9 \mathrm{~mm}, p<0.001)$. Other parameters were not significantly different between the groups. In terms of etiology, ASD caused by previous vertebral fracture was significantly higher in the PD+ group than in the PDgroup (previous vertebral fracture/degenerative/post lumbar surgery: $38.5 \% / 53.8 \% / 7.7 \%$ vs $10.1 \% / 64.7 \% /$ $25.1 \%, p=0.005)$. Of the 27 patients in the $\mathrm{PD}+$ group, 23 were taking dopamine precursors, 8 were taking dopamine agonists, and 4 were not taking any medication for PD.

Table 2 shows the surgical invasiveness and postoperative complications for both groups. There was no significant difference in operating time or intraoperative blood loss between the groups. For early complications, the $\mathrm{PD}+$ group showed a higher rate of delirium than the $\mathrm{PD}-$ group. In the $\mathrm{PD}+$ group, rates of DVT and $\mathrm{PE}$ tended to be higher (DVT: $14.8 \%$ vs $6.8 \%, p=0.12$; PE: $3.7 \%$ vs $0.5 \%, p=0.081$ ); the difference was not statistically significant. There were no differences between the groups in the rates of other complications, including neurological deficits, implant failure, cerebrovascular disorders, respiratory disorders, cardiovascular disorders, and surgical site infections. There was no significant difference in the rate of revision surgery due to early complications. For late complications, the non-union rate was significantly higher in the PD+ group $(37.0 \%$ vs $19.4 \% ; p=0.017)$. Rates of rod failure and revision surgery due to mechanical complications also tended to be higher, albeit not significantly, in the PD+ group (rod failure: $25.9 \%$ vs $13.1 \%, p=0.174$; revision surgery: $33.3 \%$ vs $18.0 \%, p=0.13$ ).

Table 3 summarizes the changes in the radiographic parameters after surgery and at the final follow-up. Postoperative SVA was similar between the two groups, although the preoperative SVA was much higher in the $\mathrm{PD}+$ group. The change in SVA on radiographs obtained before and after surgery was significantly greater in the $\mathrm{PD}+$ group $(-142.5 \pm 82.0 \mathrm{~mm}$ vs $-94.6 \pm 69.7 \mathrm{~mm}, p=$ 0.014). Furthermore, SVA at the final follow-up tended to be greater in the PD+ group $(p=0.062)$. Loss of correction of SVA also tended to be more common in the $\mathrm{PD}+$ group $(p=0.11)$. No significant difference were found for any other radiographic parameter, including the proposed ideal alignment target of PI-LL $<10$.

Table 4 presents the preoperative demographics, postoperative radiographic parameters, and surgical characteristics of the PD+ group according to whether revision surgery was required. No significant difference was found in any radiographic parameter between the two subgroups. However, the duration of PD was significantly longer in the revision subgroup than in the nonrevision subgroup $(87.0 \pm 56.9$ months vs $32.5 \pm 48.0$ months, $p=0.037$ ). HY stage was higher in the revision subgroup than in the non-revision subgroup but was not significantly different $(2.8 \pm 1.2$ vs $2.2 \pm 1.3, p=0.29)$.

Table 5 shows the demographics and postoperative complications in the PD+ and PD- groups after propensity score matching. Twenty-four pairs of patients, one with PD and one without PD, were created after matching. Age at surgery, sex, BMI, BMD, fusion levels, preoperative SVA, and LL were almost completely matched. Revision surgery due to mechanical complications tended to be higher, but not significantly, in the PD+ group (33.3\% vs $12.5 \%, p=0.086)$.

\section{Discussion}

Patients with PD have been reported to have more postoperative complications due to various musculoskeletal problems. High rates of perioperative and postoperative complications following hip and knee surgery in patients with PD have been found in studies using a nationwide inpatient database $[25,26]$. Furthermore, surgical studies on the PD population have suggested higher rates of 
Table 1 Demographic and clinical characteristics of the two study groups

\begin{tabular}{|c|c|c|c|}
\hline & PD+ group & PD- group & $p$-value \\
\hline Cases, n & 27 & 206 & - \\
\hline Age at surgery (years) & $70.6 \pm 6.3$ & $72.5 \pm 8.5$ & 0.18 \\
\hline Sex (male/female, n) & $5 / 22$ & $32 / 174$ & 0.58 \\
\hline BMl & $22.8 \pm 4.2$ & $23.2 \pm 3.7$ & 0.59 \\
\hline BMD (T-score) & $-1.900 \pm 1.249$ & $-1.863 \pm 0.924$ & 0.93 \\
\hline \multicolumn{4}{|l|}{ Medications for PD } \\
\hline Dopamine precursors (yes/no) & $23 / 4(85.2 \%)$ & - & - \\
\hline Dopamine agonists (yes/no) & $8 / 19(29.6 \%)$ & - & - \\
\hline Monoamine oxidase type B inhibitors (yes/no) & $6 / 21(22.2 \%)$ & - & - \\
\hline Other & $4 / 23(14.8 \%)$ & - & - \\
\hline \multicolumn{4}{|l|}{ Medical comorbidities } \\
\hline Diabetes (yes/no) & $1 / 26(3.7 \%)$ & $22 / 184(10.7 \%)$ & 0.49 \\
\hline Rheumatoid arthritis (yes/no) & $0 / 27$ & 9/197 (4.4\%) & 0.60 \\
\hline Renal dysfunction (yes/no) & $0 / 27$ & 19/187 (9.2\%) & 0.14 \\
\hline Cardiovascular disease (yes/no) & $2 / 25(7.4 \%)$ & $26 / 180(12.6 \%)$ & 0.75 \\
\hline Cerebrovascular disease (yes/no) & $5 / 22(18.5 \%)$ & $14 / 192(6.8 \%)$ & 0.053 \\
\hline Respiratory disease (yes/no) & $0 / 27$ & $21 / 185(10.2 \%)$ & 0.14 \\
\hline Follow-up duration (months) & $50.3 \pm 16.2$ & $49.0 \pm 14.1$ & 0.68 \\
\hline Number of fixed levels & $9.3 \pm 2.6$ & $7.8 \pm 1.9$ & 0.006 \\
\hline 3CO (yes/no) & $17 / 10$ & $100 / 106$ & 0.14 \\
\hline Etiology (post fracture/degenerative/previous lumbar fusion) & $10 / 15 / 2$ & $21 / 133 / 52$ & 0.001 \\
\hline Fix to sacrum (yes/no) & $22 / 5(81.5 \%)$ & $174 / 32(84.1 \%)$ & 0.78 \\
\hline Pre SVA (mm) & $196.0 \pm 63.7$ & $135.4 \pm 69.9$ & $<0.001$ \\
\hline Pre LL $\left(^{\circ}\right)$ & $2.1 \pm 19.3$ & $3.5 \pm 20.5$ & 0.75 \\
\hline Pre TLK $\left(^{\circ}\right)$ & $18.1 \pm 16.0$ & $19.2 \pm 17.0$ & 0.28 \\
\hline Pre TK $\left(^{\circ}\right)$ & $24.1 \pm 15.4$ & $27.4 \pm 20.0$ & 0.37 \\
\hline Pre SS $\left(^{\circ}\right)$ & $17.1 \pm 8.0$ & $14.7 \pm 11.4$ & 0.34 \\
\hline Pre PT $\left(^{\circ}\right)$ & $36.6 \pm 8.6$ & $34.5 \pm 13.2$ & 0.47 \\
\hline $\operatorname{PI}\left({ }^{\circ}\right)$ & $53.6 \pm 9.6$ & $49.8 \pm 9.1$ & 0.088 \\
\hline
\end{tabular}

$3 C O$ Three-column osteotomy, BMD Bone mineral density, BMI Bone mass index, LL Lumbar lordosis, PD Parkinson's disease, PI Pelvic incidence, $P T$ Pelvic tilt, SS Sacral slope, SVA Sagittal vertical axis, TK Thoracic kyphosis.

postoperative medical complications, including pneumonia, delirium, and sepsis [5]. However, only a few case series have examined the relationship between PD and complications following corrective surgery for ASD. Furthermore, there have been few detailed comparisons of radiographic parameters between patients with and without PD. Therefore, in this multicenter study, we retrospectively compared both postoperative complications and radiographic parameters in patients with ASD according to whether they had PD. This study has three strengths: 1) detailed data on radiographic parameters and early/late postoperative complications were collected; 2) patients with and without PD were compared using both crude analysis and propensity matching analysis; 3 ) all patients were followed up for at least 2 years; and, 4) the number of samples included had adequate statistical power.

In this study, the rate of delirium was significantly higher and the rates of PE and DVT tended to be higher in patients with PD. Our finding of a higher rate of delirium in patients with PD is consistent with that of Watanabe et al., who reported that postoperative delirium was more common in patients with PD (23.1\%) compared with a control group (3.4\%) [27]. Our patients who developed delirium were taking at least one medication for PD and had an HY stage of more than 2, which suggests that this higher rate of delirium was possibly due to use of PD drugs as well as the neurodegenerative state in patients with PD. Although delirium is thought to be a reversible condition, there have been 
Table 2 Postoperative complications in the two study groups

\begin{tabular}{|c|c|c|c|}
\hline & PD+ group & PD- group & $p$-value \\
\hline Cases, n & 27 & 206 & - \\
\hline Operating time (min) & $490 \pm 154$ & $454 \pm 113$ & 0.14 \\
\hline Blood loss (g) & $2069 \pm 1336$ & $1984 \pm 1422$ & 0.28 \\
\hline \multicolumn{4}{|l|}{ Early complications } \\
\hline Neurological (yes/no) & $3 / 24(11.1 \%)$ & 23/183 (11.2\%) & 0.96 \\
\hline Implant failure (yes/no) & $2 / 25(7.4 \%)$ & 20/186 (9.7\%) & 0.74 \\
\hline DVT (yes/no) & 4/23 (14.8\%) & 14/192 (6.8\%) & 0.12 \\
\hline PE (yes/no) & $1 / 26(3.7 \%)$ & $1 / 205(0.5 \%)$ & 0.081 \\
\hline Cerebrovascular disorder (yes/no) & $0 / 27(0 \%)$ & $2 / 204(1.0 \%)$ & 0.61 \\
\hline Respiratory disorder (yes/no) & $1 / 26(3.7 \%)$ & $7 / 199$ (3.4\%) & 0.91 \\
\hline Cardiovascular disorder (yes/no) & 0/27 (0\%) & $6 / 200(2.9 \%)$ & 0.38 \\
\hline Delirium (yes/no) & $7 / 20(25.9 \%)$ & 15/191 (7.3\%) & 0.001 \\
\hline Surgical site infection (yes/no) & $1 / 26(3.7 \%)$ & $6 / 200(2.9 \%)$ & 0.79 \\
\hline Spinal epidural hematoma (yes/no) & $0 / 27(0 \%)$ & 14/192 (6.8\%) & 0.17 \\
\hline \multicolumn{4}{|l|}{ Late complications } \\
\hline Mechanical complication (yes/no) & 15/12 (55.6\%) & 99/107 (48.1\%) & 0.59 \\
\hline Rod failure (yes/no) & $7 / 20(25.9 \%)$ & 27/179 (13.1\%) & 0.17 \\
\hline Non-union & 10/17 (37.0\%) & $34 / 172(16.5 \%)$ & 0.017 \\
\hline PJK (yes/no) & 8/19 (29.6\%) & $55 / 151(26.7 \%)$ & 0.82 \\
\hline DJK (yes/no) & 3/24 (11.1\%) & 15/191 (7.3\%) & 0.95 \\
\hline Vertebral fracture (yes/no) & $7 / 20(25.9 \%)$ & 43/163 (20.9\%) & 0.81 \\
\hline Revision (yes/no) & 9/18 (33.3\%) & $37 / 169$ (18.0\%) & 0.13 \\
\hline
\end{tabular}

DJK Distal junction kyphosis, DVT Deep vein thrombosis, PD Parkinson's disease, PE Pulmonary embolism, PJK Proximal junction kyphosis.

reports of postoperative delirium leading to prolonged hospitalization and increased morbidity and mortality rates. Further complications may also occur due to falls or movement beyond the limits of restriction. Therefore, patients with PD should be investigated carefully for modifiable risk factors, including management of sedation, deliriogenic medications, immobility, and sleep disruption. The incidence of thrombotic events was relatively high in our patients with PD but was not significantly different from that in patients without PD. However, a previous study in Japan that included data from a large nationwide database found a significantly increased risk of PE in patients with PD [28]. PE is recognized as a possible adverse reaction to dopamine precursors, such as levodopa [29]. Moreover, Yamane et al. reported a higher incidence $(20 \%)$ of DVT in patients with PD who had a postural abnormality [30]. Given that patients who undergo corrective surgery for ASD are generally at higher risk of PE due to the long operating time and the lengthy immobilization period after surgery, the risk of PE in patients undergoing surgery for ASD is likely to be high. Therefore, surgeons should consider a thrombotic event when a patient develops chest pain and dyspnea after surgery, particularly if they have PD. Preoperative screening of the D-dimer level or an ultrasound examination for DVT could be a viable preventative strategy.

In this study, we found a significantly higher preoperative SVA and greater correction of SVA in our PD+ group. We also found that the SVA at final follow-up was higher in the PD+ group. The loss of correction of SVA was also slightly higher in the PD+ group, even though more vertebral segments were fused in this group. This finding suggests that the deformities in the $\mathrm{PD}+$ group were severe but essentially flexible and were largely corrected by the surgery. However, the improved SVA was not well maintained in this group. The exact reasons for the increased SVA after surgery in patients with PD are unknown. However, the stooping posture associated with PD could in itself cause deterioration in overall sagittal balance, and this may be one of the causes of the poorer outcome in patients with PD. Kawaguchi et al. reported that longer fusion (up to the T4 level) achieved a good clinical outcome in a patient with PD after corrective surgery from L1 to S1 had been unsuccessful [31]. Watanabe et al. reported that patients with PD who were surgically treated for ASD had poor clinical outcomes and high rates of non-union and 
Table 3 Postoperative radiographic parameters in the two study groups

\begin{tabular}{|c|c|c|c|}
\hline & PD+ & PD- & $P$-value \\
\hline Cases, $n$ & 27 & 207 & - \\
\hline Post SVA (mm) & $53.5 \pm 41.6$ & $40.0 \pm 46.2$ & 0.17 \\
\hline Change in SVA (post-pre) (mm) & $-142.5 \pm 82.0$ & $-94.6 \pm 69.7$ & 0.003 \\
\hline Final SVA (mm) & $89.2 \pm 68.1$ & $59.9 \pm 52.2$ & 0.062 \\
\hline Loss of SVA correction (mm) & $35.7 \pm 62.1$ & $19.2 \pm 43.4$ & 0.11 \\
\hline Post LL $\left(^{\circ}\right)$ & $41.4 \pm 10.8$ & $39.7 \pm 11.3$ & 0.64 \\
\hline Final LL $\left(^{\circ}\right)$ & $38.6 \pm 12.3$ & $36.4 \pm 12.5$ & 0.74 \\
\hline LL correction loss $\left({ }^{\circ}\right)$ & $-0.64 \pm 20.9$ & $-0.20 \pm 21.3$ & 0.93 \\
\hline Post TK $\left({ }^{\circ}\right)$ & $37.1 \pm 12.9$ & $36.5 \pm 14.5$ & 0.85 \\
\hline Final TK $\left(^{\circ}\right)$ & $44.3 \pm 14.8$ & $43.0 \pm 16.5$ & 0.70 \\
\hline TK correction loss $\left(^{\circ}\right)$ & $7.3 \pm 7.1$ & $6.5 \pm 10.6$ & 0.87 \\
\hline Post SS $\left(^{\circ}\right)$ & $27.1 \pm 6.6$ & $26.2 \pm 8.6$ & 0.56 \\
\hline Final SS $\left(^{\circ}\right)$ & $27.4 \pm 9.6$ & $24.7 \pm 17.3$ & 0.48 \\
\hline SS correction loss $\left(^{\circ}\right)$ & $-0.3 \pm 6.4$ & $1.7 \pm 16.8$ & 0.58 \\
\hline Post PT $\left({ }^{\circ}\right)$ & $26.5 \pm 9.4$ & $23.0 \pm 10.2$ & 0.12 \\
\hline Final PT $\left(^{\circ}\right)$ & $26.2 \pm 11.3$ & $24.7 \pm 19.0$ & 0.59 \\
\hline$-10<$ post $\mathrm{Pl}-\mathrm{LL}<10$ (yes/no) & $12 / 15$ & 108/99 & 0.83 \\
\hline
\end{tabular}

LL Lumbar lordosis, PD Parkinson's disease, PI Pelvic incidence, PT Pelvic tilt, SS Sacral slope, SVA Sagittal vertical axis, TK Thoracic kyphosis.

adjacent segment disease [32]. Therefore, it is important to consider possible prevention strategies, including fusion of a greater number of segments.

In this study, the revision rate due to mechanical complications in the PD+ group was $33.3 \%$ and almost double that in the PD- group. This finding is similar to that in a study by Sheu et al., who reported that $29 \%$ of 66 patients with PD who underwent instrumented thoracolumbar or lumbar surgery for degeneration or deformity required revision surgery due to mechanical complications [15]. Bouyer et al. reported a high revision rate of $42 \%$ in 48 patients with PD who underwent surgery for ASD; the revision surgery was performed for mechanical complications in $89 \%$ of cases [18]. PJK has been reported to be significantly more common in patients with PD [5]. However, a diagnosis of PD had no significant impact on the PJK rate in this study, although rates of non-union and rod failure were higher in our $\mathrm{PD}+$ group. Even after matching for fusion levels and preoperative SVA using propensity scores, the rate of non-union tended to be higher in the PD+ group. Nonunion can initiate pain and hardware issues, such as loosening of screws and rod fracture. Therefore, the surgeon should consider prevention strategies in patients with PD, such as administration of teriparatide.

Several studies have investigated the risk factors for revision surgery in patients with PD. Schroeder et al. reported that an HY stage $>2$, diabetes mellitus, treatment
Table 4 Postoperative radiographic parameters and demographics in the PD+ group according to whether revision surgery was required

\begin{tabular}{|c|c|c|c|}
\hline & Revision & No revision & $p$-value \\
\hline Cases, n & 9 & 18 & - \\
\hline Pre SVA (mm) & $187.0 \pm 62.3$ & $193.4 \pm 63.6$ & 0.84 \\
\hline Post SVA (mm) & $60.2 \pm 27.4$ & $57.7 \pm 39.2$ & 0.87 \\
\hline Pre LL $\left(^{\circ}\right)$ & $-3.5 \pm 27.3$ & $4.9 \pm 16.3$ & 0.51 \\
\hline Post LL $\left(^{\circ}\right)$ & $33.7 \pm 13.4$ & $44.6 \pm 8.6$ & 0.11 \\
\hline Pre TLK $\left(^{\circ}\right)$ & $9.3 \pm 6.9$ & $11.2 \pm 12.5$ & 0.26 \\
\hline Post TLK $\left(^{\circ}\right)$ & $11.4 \pm 11.4$ & $0.2 \pm 11.6$ & 0.074 \\
\hline Pre TK $\left(^{\circ}\right)$ & $15.0 \pm 16.0$ & $26.3 \pm 13.7$ & 0.17 \\
\hline Post TK $\left(^{\circ}\right)$ & $30.0 \pm 18.5$ & $40.1 \pm 9.8$ & 0.25 \\
\hline Pre SS $\left(^{\circ}\right)$ & $16.2 \pm 11.8$ & $17.0 \pm 6.5$ & 0.87 \\
\hline Post SS $\left(^{\circ}\right)$ & $24.3 \pm 7.8$ & $28.5 \pm 6.2$ & 0.28 \\
\hline Pre PT $\left(^{\circ}\right)$ & $35.5 \pm 7.3$ & $37.0 \pm 9.3$ & 0.71 \\
\hline Post PT $\left(^{\circ}\right)$ & $27.3 \pm 5.2$ & $26.2 \pm 10.7$ & 0.74 \\
\hline $\mathrm{PI}\left({ }^{\circ}\right)$ & $51.7 \pm 8.7$ & $54.6 \pm 10.4$ & 0.53 \\
\hline Age at surgery (years) & $68.5 \pm 3.7$ & $71.6 \pm 6.5$ & 0.19 \\
\hline BMl & $21.9 \pm 3.7$ & $23.8 \pm 4.3$ & 0.33 \\
\hline Number of fixed levels & $9.0 \pm 2.5$ & $10.2 \pm 2.5$ & 0.35 \\
\hline Duration of PD (months) & $87.0 \pm 56.9$ & $32.5 \pm 48.0$ & 0.037 \\
\hline Hoehn and Yahr stage & $2.8 \pm 1.2$ & $2.2 \pm 1.3$ & 0.29 \\
\hline BMD (T-score) & $-2.1 \pm 1.7$ & $-1.8 \pm 1.2$ & 0.81 \\
\hline
\end{tabular}

$B M D$ Bone mineral density, BMI Bone mass index, $L L$ Lumbar lordosis, $P D$ Parkinson's disease, PI Pelvic incidence, PT Pelvic tilt, SS Sacral slope, SVA Sagittal vertical axis, TLK Thoracolumbar kyphosis, TK Thoracic kyphosis.

for osteoporosis, and a combined anterior and posterior surgical approach were risk factors for revision surgery in 94 lumbar spine surgeries [14]. According to Sheu et al., HY stage $>2$, a history of cancer, osteoporosis, and three-column osteotomy were risk factors for revision surgery [15]. Evaluation of walking ability using the HY scale can be affected by symptoms of ASD, so the stage itself may not reflect the exact severity of PD in patients undergoing ASD. However, in our study, the revision subgroup tended to have a higher HY stage and a longer duration of PD. Therefore, it is important to consider both duration and severity of PD when performing surgery in these patients.

This study has several limitations. First, the surgeons were able to select the surgical procedure based on PD status, which would introduce selection bias. Second, because the study had a multicenter design, we used simple criteria to identify mechanical complications, namely, plain radiographs. Hence, the nonunion rate may have been underestimated. Third, the patients in the PD+ and PD- groups had different background characteristics. This problem was dealt with by 
Table 5 Demographic and postoperative complications in the study groups after propensity score matching

\begin{tabular}{|c|c|c|c|}
\hline & PD+ group & PD- group & $p$-value \\
\hline Cases, $\mathrm{n}$ & 24 & 24 & - \\
\hline Age at surgery (years) & $70.8 \pm 6.5$ & $70.6 \pm 11.5$ & 0.95 \\
\hline Sex (male/female), m & $5 / 19$ & $3 / 21$ & 0.70 \\
\hline BMI & $23.2 \pm 4.1$ & $24.0 \pm 4.1$ & 0.49 \\
\hline BMD (T-score) & $-1.7 \pm 1.2$ & $-2.0 \pm 0.75$ & 0.55 \\
\hline Number of fixed levels & $9.0 \pm 2.4$ & $9.0 \pm 2.0$ & 0.95 \\
\hline 3CO (yes/no) & $7 / 17$ & $11 / 13$ & 0.37 \\
\hline Fix to sacrum (yes/no) & $24 / 0$ & $24 / 0$ & - \\
\hline Pre SVA (mm) & $185.7 \pm 62.4$ & $182.9 \pm 76.9$ & 0.89 \\
\hline Pre LL $\left(^{\circ}\right)$ & $0.04 \pm 21.8$ & $-1.0 \pm 20.0$ & 0.86 \\
\hline Mechanical complication (yes/no) & $14 / 10(58.3 \%)$ & $11 / 13(45.8 \%)$ & 0.38 \\
\hline Rod failure (yes/no) & $6 / 18(25.0 \%)$ & $4 / 20(16.7 \%)$ & 0.48 \\
\hline Non-union & 10/14 (41.7\%) & $4 / 20(16.7 \%)$ & 0.059 \\
\hline PJK (yes/no) & 7/17 (29.2\%) & 9/15 (37.5\%) & 0.54 \\
\hline DJK (yes/no) & $2 / 22(8.3 \%)$ & 0/24 (0\%) & 0.15 \\
\hline Vertebral fracture (yes/no) & $6 / 18(25.0 \%)$ & $8 / 16(33.3 \%)$ & 0.53 \\
\hline Revision (yes/no) & 8/16 (33.3\%) & $3 / 21(12.5 \%)$ & 0.086 \\
\hline Post SVA (mm) & $50.0 \pm 46.5$ & $48.3 \pm 42.8$ & 0.89 \\
\hline Post LL $\left(^{\circ}\right)$ & $41.7 \pm 10.2$ & $41.9 \pm 12.1$ & 0.95 \\
\hline Final SVA (mm) & $89.9 \pm 62.2$ & $65.6 \pm 46.9$ & 0.13 \\
\hline Final LL $\left(^{\circ}\right)$ & $39.4 \pm 12.1$ & $38.3 \pm 14.2$ & 0.95 \\
\hline SVA correction loss (mm) & $39.8 \pm 48.7$ & $17.3 \pm 38.8$ & 0.08 \\
\hline LL correction loss $\left(^{\circ}\right)$ & $-3.3 \pm 20.8$ & $-3.5 \pm 19.9$ & 0.97 \\
\hline
\end{tabular}

3CO Three-column osteotomy, BMD Bone mineral density, BMI Bone mass index, DJK Distal junction kyphosis, LL Lumbar lordosis, PD Parkinson's disease, PJK Proximal junction kyphosis, SVA Sagittal vertical axis.

propensity score matching to allow for comparison of the two groups. Fourth, the study was retrospective in nature, and the number of patients with PD was relatively low. When considering the non-union rates in our study groups, the effect size (w) was 0.376 . A subsequent post hoc analysis showed that the statistical power for the chi-square test was $\beta=0.99$ when the type I error rate $(\alpha)$ was set at 0.05 ( $G *$ power 3.1$)$. Therefore, we consider that the main results of this study, including the significant between-group difference in the nonunion rate, were based on an adequate sample size. However, this does not necessarily mean that the sample size was large enough for all of the analyses. Better designed studies that include a larger sample size are needed in the future.

Despite the above-mentioned limitations, this study yielded the following important findings: 1) patients with PD were at greater risk of developing delirium in the early postoperative period; 2) the non-union rate was significantly higher in patients with $\mathrm{PD}$; and 3) the rate of revision surgery tended to be higher in patients with $\mathrm{PD}$ in the late postoperative period.

\section{Conclusion}

Postoperative delirium was common in patients with PD. Late complications included rod fracture, nonunion, and revision surgery, and occurred more frequently in patients with PD. The rate of revision surgery due to mechanical complications in patients with PD was approximately double that of their counterparts without PD. In patients with PD, the SVA was significantly larger before surgery and at final follow-up, as was the loss of correction of SVA, suggesting that PDspecific postural abnormalities are involved in deterioration of the sagittal parameters. The duration of PD was significantly longer in patients who underwent revision surgery than in those who did not.

\section{Abbreviations}

ASD: Adult spinal deformity; BMI: Body mass index; BMD: Bone mineral density; DVT: Deep vein thrombosis; DJK: Distal junctional kyphosis; HY: Hoehn and Yahr; LL: L1-S1 lumbar lordosis; PD: Parkinson's disease; PI: Pelvic incidence; PJK: Proximal junctional kyphosis; PE: Pulmonary embolism; T4-T10: Thoracic kyphosis; UIV: Upper instrumented vertebra

Acknowledgements Not applicable. 


\section{Authors' contributions}

AK analysed the data and wrote the original draft. TY conceived of, reviewed, and edited the paper. SM, KS, TH, MY, HI, YM, MT, IT, and KK acquired the data. $\mathrm{KO}$ performed the investigation. YA validated the paper. YA, SS, and AO supervised the researched. All authors contributed to the writing of the final manuscript. All authors approved the manuscript to be published and agree to be accountable for all aspects of the work in ensuring that questions related to the accuracy or integrity of any part of the work are appropriately investigated and resolved.

\section{Funding}

Not applicable.

\section{Availability of data and materials}

The datasets generated during and/or analyzed during the current study are available from the corresponding author on reasonable request.

\section{Declarations}

\section{Ethics approval and consent to participate}

The study was approved by the ethics committee of all institutions involved. Informed consent was waived by the following ethics committee because the present retrospective cohort study involved already existing data and records at the time of investigation and did not retain personal identifiers of the gathered information.

The ethical committee, Tokyo Medical and Dental University; M2017-115.

The ethical committee, Saiseikai Kawaguchi General Hospital; 29-2.

The ethical committee, Kudanzaka Hospital; 2019-5.

\section{Consent for publication}

Not applicable.

\section{Competing interests}

Not applicable.

\section{Author details}

'Department of Orthopedic Surgery, Tokyo Medical and Dental University, 1 Chome-5-45 Yushima, Bunkyo City, Tokyo 113-8510, Japan. 'Department of Orthopedic Surgery, Saiseikai Kawaguchi General Hospital, 5 Chome-11-5 Nishikawaguchi, Kawaguchi, Saitama 332-8558, Japan. ${ }^{3}$ Department of Orthopedic Surgery, Kudanzaka Hospital, 1 Chome-6-12 Kudanminami, Chiyoda, Tokyo 102-0074, Japan.

\section{Received: 31 January 2020 Accepted: 8 April 2021}

\section{Published online: 16 April 2021}

\section{References}

1. de Lau LM, Breteler MM. Epidemiology of Parkinson's disease. Lancet Neurol. 2006;5(6):525-35. https://doi.org/10.1016/S1474-4422(06)70471-9.

2. Doherty KM, Davagnanam I, Molloy S, Silveira-Moriyama L, Lees AJ. Pisa syndrome in Parkinson's disease: a mobile or fixed deformity? J Neurol Neurosurg Psychiatry. 2013;84(12):1400-3. https://doi.org/10.1136/jnnp-2 012-304700

3. Ye X, Lou D, Ding X, Xie C, Gao J, Lou Y, et al. A clinical study of the coronal plane deformity in Parkinson disease. Eur Spine J. 2017;26(7):1862-70. https://doi.org/10.1007/s00586-017-5018-6.

4. Alwardat M, Schirinzi T, Di Lazzaro G, Franco D, Sinibaldi Salimei P, Mercuri $N B$, et al. The effect of postural deformities on back function and pain in patients with Parkinson's disease. NeuroRehabilitation. 2019;44(3):419-24. https://doi.org/10.3233/NRE-182637.

5. Protopsaltis TS, Boniello AJ, Schwab FJ. Management of Spinal Deformity in adult patients with neuromuscular disease. J Am Acad Orthop Surg. 2016; 24(9):634-44. https://doi.org/10.5435/JAAOS-D-15-00421.

6. Marsden CD, Duvoisin R. Scoliosis and Parkinson's disease. Arch Neurol. 1980;37(4):253-4. https://doi.org/10.1001/archneur.1980.00500530091025.

7. Schwab FJ, Blondel B, Bess S, Hostin R, Shaffrey Cl, Smith JS, et al. Radiographical spinopelvic parameters and disability in the setting of adult spinal deformity: a prospective multicenter analysis. Spine (Phila Pa 1976). 2013;38(13):E803-12. https://doi.org/10.1097/BRS.0b013e318292b7b9.

8. Scheer JK, Tang JA, Smith JS, Klineberg E, Hart RA, Mundis GM, et al. Reoperation rates and impact on outcome in a large, prospective, multicenter, adult spinal deformity database: clinical article. J Neurosurg Spine. 2013;19(4):464-70. https://doi.org/10.3171/2013.7.SPINE12901.

9. Acaroglu E, Yavuz AC, Guler UO, Yuksel S, Yavuz Y, Domingo-Sabat M, et al. A decision analysis to identify the ideal treatment for adult spinal deformity: is surgery better than non-surgical treatment in improving health-related quality of life and decreasing the disease burden? Eur Spine J. 2016;25(8): 2390-400. https://doi.org/10.1007/s00586-016-4413-8.

10. Charosky S, Guigui P, Blamoutier A, Roussouly P, Chopin D. Scoliosis SGo: complications and risk factors of primary adult scoliosis surgery: a multicenter study of 306 patients. Spine (Phila Pa 1976). 2012;37(8):693-700. https://doi.org/10.1097/BRS.0b013e31822ff5c1.

11. Hallager DW, Karstensen S, Bukhari N, Gehrchen M, Dahl B. Radiographic predictors for mechanical failure after adult spinal deformity surgery: a retrospective cohort study in 138 patients. Spine (Phila Pa 1976). 2017; 42(14):E855-63. https://doi.org/10.1097/BRS.0000000000001996.

12. Baker JF, McClelland S, Line BG, Smith JS, Hart RA, Ames CP, et al. In-hospital complications and resource utilization following lumbar spine surgery in patients with Parkinson disease: evaluation of the National Inpatient Sample Database. World Neurosurg. 2017;106:470-6. https://doi.org/10.1016/j. wneu.2017.07.006

13. Kimura H, Fujibayashi S, Otsuki B, Takemoto M, Shikata J, Odate S, et al. Lumbar spinal surgery in patients with Parkinson disease: a multicenter retrospective study. Clin Spine Surg. 2017;30(6):E809-18. https://doi.org/10.1 097/BSD.0000000000000455

14. Schroeder JE, Hughes A, Sama A, Weinstein J, Kaplan L, Cammisa FP, et al. Lumbar spine surgery in patients with Parkinson disease. J Bone Joint Surg Am. 2015;97(20):1661-6. https://doi.org/10.2106/JBJS.N.01049.

15. Sheu H, Liao JC, Lin YC. The fate of thoracolumbar surgeries in patients with Parkinson's disease, and analysis of risk factors for revision surgeries. BMC Musculoskelet Disord. 2019;20(1):106. https://doi.org/10.1186/s12891-019-2481-8.

16. Bourghli A, Guérin P, Vital JM, Aurouer N, Luc S, Gille $O$, et al. Posterior spinal fusion from $\mathrm{T} 2$ to the sacrum for the management of major deformities in patients with Parkinson disease: a retrospective review with analysis of complications. J Spinal Disord Tech. 2012;25(3):E53-60. https:// doi.org/10.1097/BSD.0b013e3182496670.

17. Babat LB, McLain RF, Bingaman W, Kalfas I, Young P, Rufo-Smith C. Spinal surgery in patients with Parkinson's disease: construct failure and progressive deformity. Spine (Phila Pa 1976). 2004;29(18):2006-12. https:// doi.org/10.1097/01.brs.0000138306.02425.21.

18. Bouyer B, Scemama C, Roussouly P, Laouissat F, Obeid I, Boissière $L$, et al. Evolution and complications after surgery for spine deformation in patients with Parkinson's disease. Orthop Traumatol Surg Res. 2017;103(4):517-22. https://doi.org/10.1016/j.otsr.2016.12.024.

19. Koller H, Acosta F, Zenner J, Ferraris L, Hitzl W, Meier O, et al. Spinal surgery in patients with Parkinson's disease: experiences with the challenges posed by sagittal imbalance and the Parkinson's spine. Eur Spine J. 2010;19(10): 1785-94. https://doi.org/10.1007/s00586-010-1405-y.

20. Glattes RC, Bridwell KH, Lenke LG, Kim YJ, Rinella A, Edwards C. Proximal junctional kyphosis in adult spinal deformity following long instrumented posterior spinal fusion: incidence, outcomes, and risk factor analysis. Spine (Phila Pa 1976). 2005;30(14):1643-9. https://doi.org/10.1097/01.brs.00001694 51.76359.49.

21. Kim YJ, Bridwell KH, Lenke LG, Rhim S, Cheh G. Pseudarthrosis in long adult spinal deformity instrumentation and fusion to the sacrum: prevalence and risk factor analysis of 144 cases. Spine (Phila Pa 1976). 2006;31(20):2329-36. https://doi.org/10.1097/01.brs.0000238968.82799.d9.

22. Okuzono S, Fujiwara T, Kato T, Kawachi I. Spanking and subsequent behavioral problems in toddlers: a propensity score-matched, prospective study in Japan. Child Abuse Negl. 2017;69:62-71. https://doi.org/10.1016/j. chiabu.2017.04.002.

23. Fang CX, Liu R, Yee DKH, Chau J, Lau TW, Chan R, et al. Comparison of radiological and clinical outcomes, complications, and implant removals in anatomically pre-contoured clavicle plates versus reconstruction plates - a propensity score matched retrospective cohort study of 106 patients. BMC Musculoskelet Disord. 2020;21(1):413. https://doi.org/10.1186/s12891-02003445-5.

24. Yagi M, Fujita N, Tsuji O, Nagoshi N, Asazuma T, Ishii K, et al. Low bonemineral density is a significant risk for proximal Junctional failure after surgical correction of adult spinal deformity: a propensity score-matched analysis. Spine (Phila Pa 1976). 2018;43(7):485-91. https://doi.org/10.1097/ BRS.0000000000002355. 
25. Newman JM, Sodhi N, Wilhelm AB, Khlopas A, Klika AK, Naziri Q, et al. Parkinson's disease increases the risk of perioperative complications after total knee arthroplasty: a nationwide database study. Knee Surg Sports Traumatol Arthrosc. 2019;27(7):2189-95. https://doi.org/10.1007/s00167-01 8-4970-y.

26. Min H, Lin H, Chen G. Effect of Parkinson's disease on primary total joint arthroplasty outcomes: a meta-analysis of matched control studies. Int J Surg. 2019;71:124-31. https://doi.org/10.1016/j.jiju.2019.09.013.

27. Watanabe K, Katsumi K, Ohashi M, Shibuya Y, Izumi T, Hirano T, et al. Surgical outcomes of spinal fusion for osteoporotic thoracolumbar vertebral fractures in patients with Parkinson's disease: what is the impact of Parkinson's disease on surgical outcome? BMC Musculoskelet Disord. 2019; 20(1):103. https://doi.org/10.1186/s12891-019-2473-8.

28. Oichi T, Chikuda H, Ohya J, Ohtomo R, Morita K, Matsui H, et al. Mortality and morbidity after spinal surgery in patients with Parkinson's disease: a retrospective matched-pair cohort study. Spine J. 2017;17(4):531-7. https:// doi.org/10.1016/j.spinee.2016.10.024

29. Hung SC, Tai CT. Parkinson's disease with recurrent pulmonary embolism. Zhonghua Yi Xue Za Zhi (Taipei). 2000;63(6):487-91.

30. Yamane K, Kimura F, Unoda K, Hosokawa T, Hirose T, Tani H, et al. Postural abnormality as a risk marker for leg deep venous thrombosis in Parkinson's disease. PLoS One. 2013;8(7):e66984. https://doi.org/10.1371/journal.pone. 0066984.

31. Kawaguchi Y, Nakano M, Seki S, Yasuda T, Hori T, Tanaka K, et al. Surgical treatment of lumbar vertebral collapse in a patient with Parkinson's disease: a case report. Eur J Orthop Surg Traumatol. 2013;23(Suppl 2):S165-70.

32. Watanabe K, Homma T, Yamazaki A. Surgical outcomes of spinal fusion surgery for lumbar degenerative scoliosis in patients with Parkinson's disease : reconstruction failure and progressive deformity. J Spine Res. 2011; 2(11):1911-20

\section{Publisher's Note}

Springer Nature remains neutral with regard to jurisdictional claims in published maps and institutional affiliations.

Ready to submit your research? Choose BMC and benefit from:

- fast, convenient online submission

- thorough peer review by experienced researchers in your field

- rapid publication on acceptance

- support for research data, including large and complex data types

- gold Open Access which fosters wider collaboration and increased citations

- maximum visibility for your research: over $100 \mathrm{M}$ website views per year

At $\mathrm{BMC}$, research is always in progress.

Learn more biomedcentral.com/submissions 